\title{
VEGI downregulation is correlated with nodal metastasis and poor prognosis in lung adenocarcinoma
}

\author{
YINHAI XU ${ }^{1 *}$, ZHAO LIU $^{2 *}, \mathrm{HAM} \mathrm{LI}^{3}, \mathrm{SHOUJIE} \mathrm{FENG}^{4}$, QINGPENG LI ${ }^{4}, \mathrm{JUNFENG} \mathrm{LI}^{5}$ and $\mathrm{SHIBAO} \mathrm{LI}^{1,6}$ \\ Departments of ${ }^{1}$ Laboratory Medicine and ${ }^{2}$ Thyroid and Breast Surgery, Affiliated Hospital of Xuzhou Medical University, \\ Xuzhou, Jiangsu 221002; ${ }^{3}$ School of Foreign Studies, Jiangsu Normal University, Xuzhou, Jiangsu 221116; \\ ${ }^{4}$ Department of Thoracic Cardiovascular Surgery, Affiliated Hospital of Xuzhou Medical University, Xuzhou, Jiangsu 221002; \\ ${ }^{5}$ Department of Endocrinology, Renmin Hospital of Wuhan University, Wuhan, Hubei 430060; \\ ${ }^{6}$ School of Medical Technology, Xuzhou Medical University, Xuzhou, Jiangsu 221004, P.R. China
}

Received October 24, 2017; Accepted July 11, 2020

DOI: $10.3892 / \operatorname{mco} .2020 .2187$

\begin{abstract}
Although the incidence of lung cancer is increasing worldwide, the molecular mechanisms for its tumorigenesis, progression and prognosis remain unknown. As a member of the tumor necrosis factor superfamily, vascular endothelial growth inhibitor (VEGI) is involved in the development and progression of many malignant diseases. In the present study, the expression of VEGI and CD31 was examined via immunohistochemistry in non-small cell lung cancer (NSCLC) tissues obtained from 150 patients with NSCLC. The inhibitory effect of VEGI on tumor-associated blood vessel formation and growth was investigated by determining the relationship between VEGI protein expression and microvascular density (MVD). Prognostic significance was evaluated using the Kaplan-Meier method. VEGI expression was downregulated or lost in $68.7 \%$ $(103 / 150)$ of patients with NSCLC, an effect that was more prevalent in adenocarcinoma (AC), 76.0\% (57/75), than in squamous cell carcinoma, $61.3 \%$ (46/75). A significant negative correlation was indentified between VEGI expression and lymphovascular invasion $(\mathrm{P}=0.039)$ and lymph node metastasis $(\mathrm{P}=0.017)$ in $\mathrm{AC}$ tissue. Additionally, MVD was significantly lower in the VEGI-rich group compared with the VEGI-poor group. The downregulation of VEGI expression was also associated with poorer overall survival $(\mathrm{P}=0.011)$ in patients with
\end{abstract}

Correspondence to: Professor Junfeng Li, Department of Endocrinology, Renmin Hospital of Wuhan University, 99 Zhangzhidong Road, Wuhan, Hubei 430060, P.R. China

E-mail: lijunfenghb@163.com

Professor Shibao Li, Department of Laboratory Medicine, Affiliated Hospital of Xuzhou Medical University, 99 West Huaihai Road, Xuzhou, Jiangsu 221002, P.R. China

E-mail: sdjnshlb@126.com

*Contributed equally

Key words: non-small cell lung cancer, vascular endothelial growth inhibitor, prognosis
AC. The present study therefore provides evidence that VEGI may be a new and effective prognostic marker of lung AC.

\section{Introduction}

Lung cancer, as the leading cause of deaths due to cancer worldwide, maksitself a global public health problem (1-3). In 2017, it was estimated that there was 22.25 million new cases of lung cancer and 15.69 million new deaths in the United States (4). With the rapid increase in industrialization and aging population in China, more patients have been diagnosed with lung cancer in recent years (5). Approximately $80 \%$ of all lung cancer cases are attributable to an aggressive and highly invasive tumor: non-small cell lung cancer (NSCLC) $(6,7)$. Due to the lack of sensitive screening tests for early diagnosis of lung cancer, and the ineffectiveness of the current treatments for advanced and metastatic cancer, the 5-year survival rate of NSCLC patients is less than $15 \%(7,8)$. Thus, it is imperative to develop early detection strategies to facilitate a timely diagnosis of primary or recurring cancers. This requires a better understanding of the molecular causes and evolution of the disease to enable the design of more effective treatments and improve the prognosis of lung cancer.

Vascular endothelial growth inhibitor (VEGI), an anti-angiogenic cytokine that inhibits the neovasculature, is a potential therapeutic target for the angiogenesis-related diseases, especially malignant neoplasms. Previous studies (9-14) have demonstrated that VEGI expression is down-regulated in many solid tumors, including mammary tumors, bladder cancer, malignant melanoma, prostate cancer, kidney cancer, colorectal cancer, and renal cell carcinoma. Moreover, its down-regulation is associated with low patient survival rates. Several studies $(15,16)$ on the role of the recombinant human VEGI found that systemic administration of VEGI significantly inhibited the growth of tumors and markedly prolonged the survival duration in the Lewis lung cancer murine tumor model, implying that VEGI possess anti-tumor effects in lung cancer. However, the expression and role of VEGI in NSCLC remains unknown. Here, the expression of VEGI protein in human NSCLC tissues and its role in NSCLC progress was evaluated and explored. 


\section{Materials and methods}

Patients and tissue specimens. One hundred and fifty NSCLC specimens, including 75 adenocarcinoma (AC) and 75 squamous cell carcinoma (SCC), were obtained from patients undergoing surgical resection due to lung cancer between July 2008 and February 2016 at the department of Cardiothoracic Surgery, of the Affiliated Hospital of Xuzhou Medical University (Jiangsu, China). All patients had definite pathological diagnosis after surgery. Patients who received adjuvant therapy were excluded. Written informed consent was obtained from all patients before tissue acquisition. Staging was performed after pathological examination of the formalin-fixed specimens according to the current seventh edition of the TNM classification. The clinical and biological data from the patients are listed in Table I. All patients were followed up every 3-6 months for two years post-operatively. After the second year, every patient was followed-up on a yearly basis until death or the last date of follow-up (November 1st, 2017). The median follow up period for the population studied was 54.5 months (range, 20-89 months). This study gained approval from the Ethics Committee of the Affiliated Hospital of Xuzhou Medical University.

Immunohistochemistry. Immunostainings were performed as per the standard protocols. Briefly, de-paraffinized in xylene, rehydrated using graded alcohols firstly, $4 \mu \mathrm{m}$ thick tissue sections, then, were incubated in acitrate buffer at a $\mathrm{pH}$ of 6.1 for $15 \mathrm{~min}$ to retrieve the antigen. To remove the endogenous peroxidase activity and reduce background non-specific staining, sections were treated with freshly prepared $3 \%$ hydrogen peroxide for $10 \mathrm{~min}$ and incubated with $10 \%$ goat non-immune serum for $20 \mathrm{~min}$. Thenceforth, after incubation with the goat anti-VEGI polyclonal antibody (1:100, cat. no. sc-23185, Santa Cruz Biotechnology, Inc.) or mouse anti-CD31 monoclonal antibody $(1: 80,3528$, Cell Signaling Technology) at $37^{\circ} \mathrm{C}$ for $1 \mathrm{~h}(\mathrm{~h})$, the sections were incubated with biotin-labeled secondary antibody (Invitrogen) at $37^{\circ} \mathrm{C}$ for $20 \mathrm{~min}$, and then incubated with HRP-conjugated streptavidin (Invitrogen) at $37^{\circ} \mathrm{C}$ for $30 \mathrm{~min}$. The color development was performed with a DAB Substrate kit (Dako). At last, the sections were counterstained with dehydrated, cleared and mounted hematoxylin. Appropriate negative controls were carried out by excluding the primary antibody and/or replacing it with an irrelevant anti-serum (no data shown).

Evaluation of VEGI expression. The evaluation of the immune histochmical staining of VEGI was based on the calculation of the percentage and intensity of the positive cells (per section by two independent pathologists). On the basis of the percentage of the positive tumor cells, the immunoreactivity of the tumor cells for VEGI was scored as follows: $0=$ no cell stained, $1=1$ to $25 \%$ of cells stained, $2=26$ to $50 \%$ of cells stained, $3=51$ to $75 \%$ of cells stained and $4=$ more than $75 \%$ of cells stained. The intensity of positive tumor cells was graded as follows: 0 for negative staining, 1 for weak staining, 2 for moderate staining, and 3 for strong staining. Scores for the intensity and percentage of positive cells were multiplied. Finally, when the total score was below 2, the classification of the expression of VEGI was considered as negative/weak, while when the total score was above 3 , it was classified as moderate/high. He expression of VEGI was negative/weak moderate/high if the total score was $\geq 3$.

Evaluation of tumor angiogenesis. The immunohistochemical staining of CD31 was used for microvascular density (MVD) counting as described previously (17). Briefly, the vessel hot spot regions with immune reactivity against CD31 were identified under magnification, x100 and the number of MVD was counted manually in 5 hot spots selected randomly at x 400 .

Statistical analysis. All statistical analyses were achieved with SPSS v16.0 software (SPSS, Inc.). Chi-square test was used to assess the correlation between VEGI protein expression and clinicopathological variables. The Student's t-test was evaluated the difference of MVD in different group. Survival curves were constructed by means of the Kaplan-Meier and the differences between the curves were compared by the log-rank test. $\mathrm{P}<0.05$ was considered to indicate a statistically significant difference.

\section{Results}

Expression of VEGI protein in NSCLC. The immunostaining of VEGI protein was represented as particles in the cytoplasm and the cell membrane which was $31.3 \%$ (47/150) in NSCLC patients (Fig. 1A and C). However, the VEGI expression was lost or weak in 103 (68.7\%) out of 150 NSCLC patients, which was significantly higher in AC, $76.0 \%$ (57/75), than in SCC, $61.3 \%$ (46/75) (Table I).

Correlation between VEGI protein expression and MVD. To investigate whether VEGI exert an inhibitory effect on tumor-associated blood vessel formation and growth, we estimated the intratumoral microvessel density (MVD) by measuring CD31-positive staining, which was mainly detected in vascular endothelial cell membrane and a lower degree in the cytoplasm. MVD was significantly lower in VEGI-rich group than in the VEGI-poor group ( $\mathrm{P}=0.01$; Fig. 2), indicating that VEGI may pose an inhibitory effect on tumor-associated blood vessel formation and growth, at least partially.

Correlation between VEGI protein expression and the clinicopathological parameters. The relationship between the VEGI expression and the clinicopathological features was analyzed in 150 NSCLC patients (Table I). Significant correlation between VEGI expression and clinicopathological parameters was not observed. Nevertheless, the down-regulation of VEGI tended to be associated with the histopathological type $(\mathrm{P}=0.059)$, lymphovascular invasion type $(\mathrm{P}=0.065)$ as well as the lymph node metastasis type $(\mathrm{P}=0.057)$, but this trend was likely due to the association with $\mathrm{AC}$.

Subsequently, the association of VEGI with clinicopathological variables classified according to their histology type was investigated (Table II). In AC patients, the down-regulation of VEGI protein was observed in $91.3 \%$ (21/23) of cases with lymphovascular invasion, and in $88.6 \%(31 / 35)$ of cases with lymph node metastasis. A strong correlation was found between VEGI expression and lymphovascular invasion 

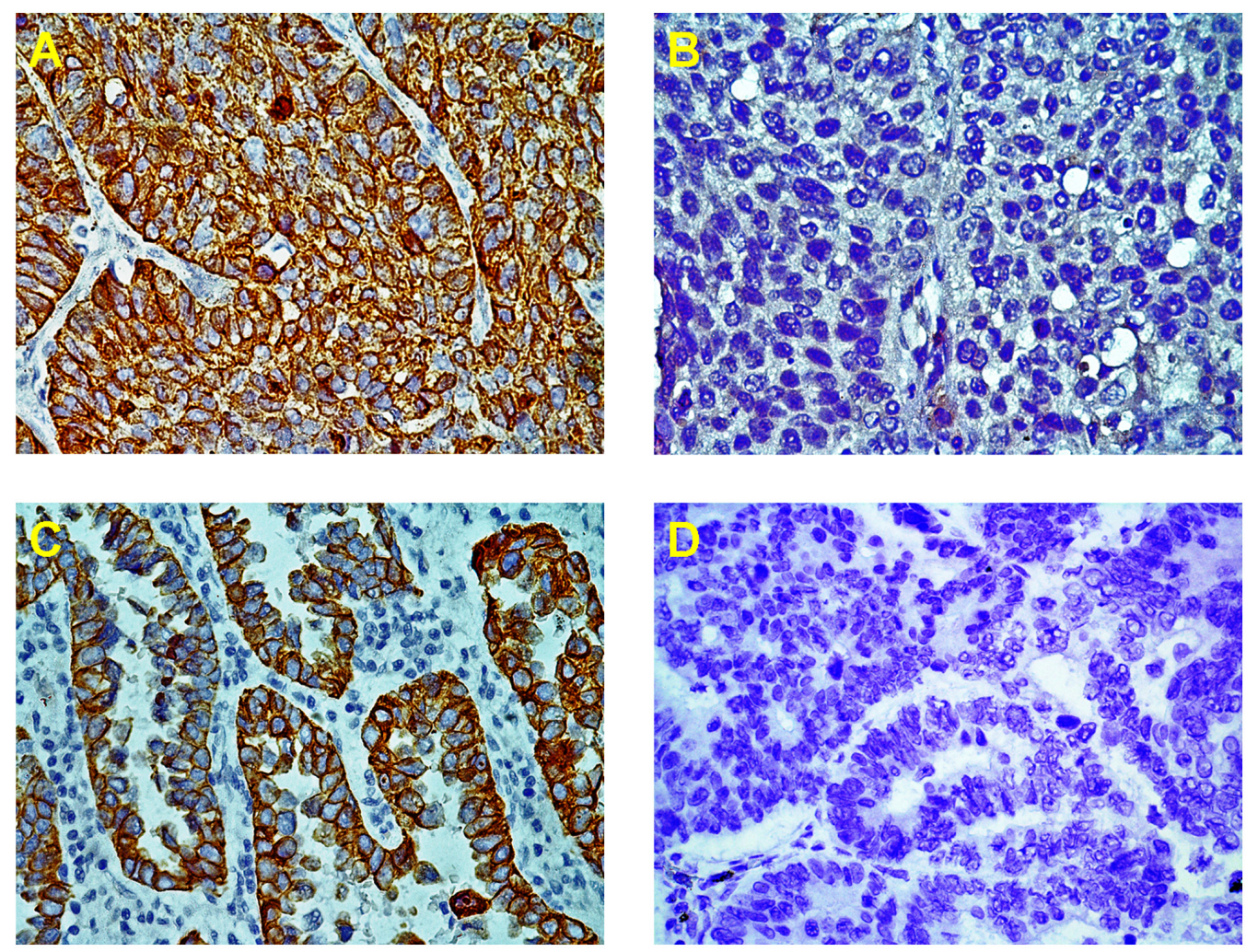

Figure 1. Representative immunostaining of vascular endothelial growth inhibitor protein expression in NSCLC lesions (magnification, $\mathrm{x} 400$ ). (A) Positive staining in the cytoplasm of NSCLC squamous type tumor cells. (B) Negative staining in the cytoplasm and nucleus of NSCLC squamous type tumor cells. (C) Positive staining in the cytoplasm of NSCLC adenocarcinoma type tumor cells. (D) Negative staining in the cytoplasm and nucleus of NSCLC adenocarcinoma type tumor cells. NSCLC, non-small cell lung cancer.
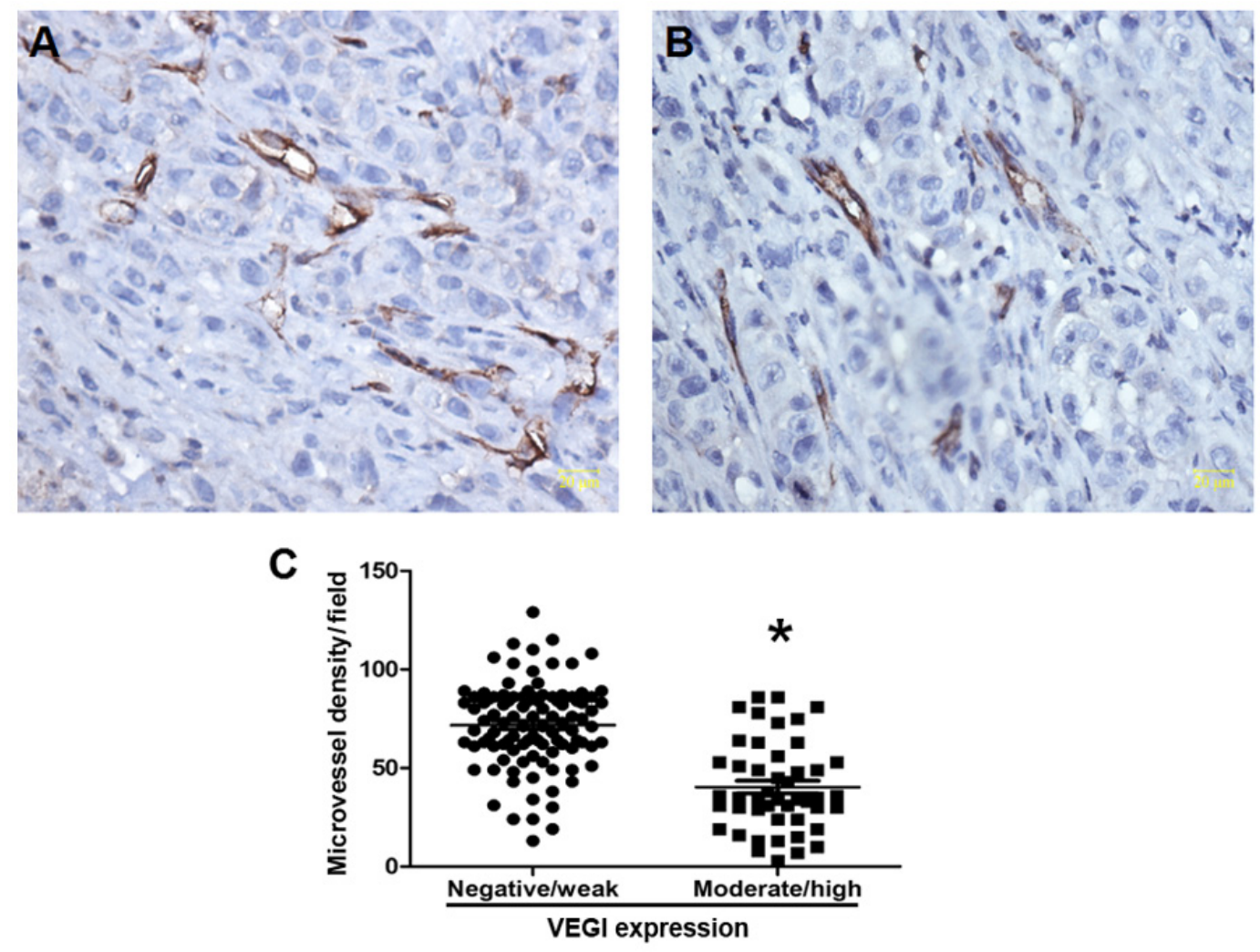

Figure 2. Association between VEGI protein expression and MVD. (A) Representative immunostaining of CD31 protein expression in NSCLC lesions with weak VEGI expression. (B) Representative immunostainings of CD31 protein expression in NSCLC lesions with moderate VEGI expression. (C) The quantification of microvessel density in different VEGI expressed NSCLC lesions. "P<0.001 vs. Negative/weak. VEGI, vascular endothelial growth inhibitor; MVD, microvascular density; NSCLC, non-small cell lung cancer. 
Table I. Association of VEGI expression with the clinicopathological characteristics of 150 patients with NSCLC.

\begin{tabular}{|c|c|c|c|c|}
\hline \multirow[b]{2}{*}{ Characteristics } & \multirow[b]{2}{*}{ Case, $\mathrm{n}(\%)$} & \multicolumn{2}{|c|}{ VEGI expression } & \multirow[b]{2}{*}{ P-value } \\
\hline & & Negative/weak & Moderate/high & \\
\hline Sex & & & & 0.738 \\
\hline Male & $109(72.7)$ & 74 & 35 & \\
\hline Female & $41(27.3)$ & 29 & 12 & \\
\hline Age, years & & & & 0.164 \\
\hline$\leq 60$ & $61(40.7)$ & 38 & 23 & \\
\hline$>60$ & $89(59.3)$ & 65 & 24 & \\
\hline Smoking & & & & 0.487 \\
\hline Yes & $116(77.3)$ & 78 & 38 & \\
\hline No & $34(22.7)$ & 25 & 9 & \\
\hline Histopathological type & & & & 0.053 \\
\hline $\mathrm{AC}$ & $75(50.0)$ & 57 & 18 & \\
\hline $\mathrm{SCC}$ & $75(50.0)$ & 46 & 29 & \\
\hline Tumor location & & & & 0.301 \\
\hline Left & $61(40.7)$ & 39 & 22 & \\
\hline Right & $89(59.3)$ & 64 & 25 & \\
\hline Histopathological grade & & & & 0.566 \\
\hline $\mathrm{I}+\mathrm{II}$ & $113(75.3)$ & 79 & 34 & \\
\hline III & $37(24.7)$ & 24 & 13 & \\
\hline Lymphovascular invasion & & & & 0.065 \\
\hline Yes & $33(22.0)$ & 27 & 6 & \\
\hline No & $117(78.0)$ & 76 & 41 & \\
\hline Tumor size & & & & 0.832 \\
\hline $\mathrm{T} 1$ & $40(26.7)$ & 28 & 12 & \\
\hline $\mathrm{T} 2-4$ & $110(73.3)$ & 75 & 35 & \\
\hline Lymph node metastasis & & & & 0.057 \\
\hline Yes & $65(43.3)$ & 50 & 15 & \\
\hline No & $85(56.7)$ & 53 & 32 & \\
\hline
\end{tabular}

VEGI, vascular endothelial growth inhibitor; NSCLC, non-small cell lung cancer; AC, adenocarcinoma; SCC, squamous cell carcinoma.

( $\mathrm{P}=0.039)$ and lymph node metastasis $(\mathrm{P}=0.017$; Table II). No correlation was observed in the squamous carcinoma group.

Correlation of VEGI tissue expression status with prognosis of NSCLC patients. To further investigate the clinical significance of VEGI expression in lung cancer, the follow-up was performed on the patients. Patients with moderate/high expression of VEGI seemed to have a longer survival period than those with negative/weak VEGI expression, and was correlated with disease-free survival ( $\mathrm{P}=0.021$; Fig. 3A). Moreover, analysis of data from a published study including 1926 lung cancer cases, available on the kmplotwebsite (http://www. kmplot.com/analysis/index.php?p=background), revealed that 967 patients who displayed the low expression of VEGI mRNA in lung tumor tissues had shorter disease free time compared with the 959 cases whose VEGI mRNA expression levels were high in lung tumor tissues (Fig. 3B). These data strongly indicate that the expression of VEGI correlates with the prognosis of NSCLC patients.
Then, a further analysis was performed within each NSCLC histopathological type because there was a significant correlation between VEGI expression and lung AC. In AC, patients with negative/weak VEGI expression had poorer overall survival than those with moderate/high VEGI expression ( $\mathrm{P}=0.011$; Fig. 3C). In contrast, these effects were not observed in patients with squamous carcinoma ( $\mathrm{P}=0.692$; Fig. 3D).

\section{Discussion}

In the present study, we investigated the expression of VEGI protein in tissue samples obtained from NSCLC patients and analyzed the correlation between the expression level of VEGI and the clinicopathological parameters. To our knowledge, this is the first study to explore the clinical significance of VEGI protein levels in NSCLC patients.

Accumulating evidence have confirmed that neovascularization is one of the most critical steps for the progress and metastasis of lung tumor because angiogenesis provides 
Table II. Association of VEGI expression with the clinicopathological characteristics of patients with AC and SCC.

\begin{tabular}{|c|c|c|c|c|c|c|c|c|}
\hline \multirow[b]{2}{*}{ Characteristics } & \multirow[b]{2}{*}{$\begin{array}{l}\text { Case, } \\
\mathrm{n}(\%)\end{array}$} & \multicolumn{2}{|c|}{ VEGI expression (AC) } & \multirow[b]{2}{*}{ P-value } & \multirow[b]{2}{*}{$\begin{array}{l}\text { Case, } \\
\mathrm{n}(\%)\end{array}$} & \multicolumn{2}{|c|}{ VEGI expression (SCC) } & \multirow[b]{2}{*}{ P-value } \\
\hline & & $\begin{array}{l}\text { Negative/ } \\
\text { weak }\end{array}$ & $\begin{array}{c}\text { Moderate/ } \\
\text { high }\end{array}$ & & & $\begin{array}{l}\text { Negative/ } \\
\text { weak }\end{array}$ & $\begin{array}{c}\text { Moderate/ } \\
\text { high }\end{array}$ & \\
\hline Sex & & & & 0.828 & & & & 0.166 \\
\hline Male & $70(93.3)$ & 53 & 17 & & $39(52.0)$ & 21 & 18 & \\
\hline Female & $5(6.7)$ & 4 & 1 & & $36(48.0)$ & 25 & 11 & \\
\hline Age, years & & & & 0.472 & & & & 0.422 \\
\hline$\leq 60$ & $24(32.0)$ & 17 & 7 & & 37 (49.3) & 21 & 16 & \\
\hline$<60$ & $51(68.0)$ & 40 & 11 & & $38(50.7)$ & 25 & 13 & \\
\hline Smoking & & & & 0.625 & & & & 0.330 \\
\hline Yes & $64(85.3)$ & 48 & 16 & & $52(69.3)$ & 30 & 22 & \\
\hline No & $11(14.7)$ & 9 & 2 & & $23(30.7)$ & 16 & 7 & \\
\hline Tumor location & & & & 0.564 & & & & 0.436 \\
\hline Left & $29(38.7)$ & 21 & 8 & & $32(42.7)$ & 18 & 14 & \\
\hline Right & $46(61.3)$ & 36 & 10 & & $43(57.3)$ & 28 & 15 & \\
\hline Histopathological grade & & & & 0.463 & & & & 0.810 \\
\hline $\mathrm{I}+\mathrm{II}$ & $55(73.3)$ & 43 & 12 & & $58(77.3)$ & 36 & 22 & \\
\hline III & $20(26.7)$ & 14 & 6 & & $17(22.7)$ & 10 & 7 & \\
\hline Lymphovascular invasion & & & & 0.039 & & & & 0.924 \\
\hline Yes & $23(30.7)$ & 21 & 2 & & $10(13.3)$ & 6 & 4 & \\
\hline No & $52(69.3)$ & 36 & 16 & & $65(86.7)$ & 40 & 25 & \\
\hline Tumor size & & & & 0.074 & & & & 0.068 \\
\hline $\mathrm{T} 1(40)$ & $21(28.0)$ & 13 & 8 & & $19(25.3)$ & 15 & 4 & \\
\hline $\mathrm{T} 2-4(110)$ & $54(72.0)$ & 44 & 10 & & $56(74.7)$ & 31 & 25 & \\
\hline Lymph node metastasis & & & & 0.017 & & & & 0.772 \\
\hline Yes & $35(46.7)$ & 31 & 4 & & $30(40.0)$ & 19 & 11 & \\
\hline No & $40(53.3)$ & 26 & 14 & & $45(60.0)$ & 27 & 18 & \\
\hline
\end{tabular}

VEGI, vascular endothelial growth inhibitor; AC, adenocarcinoma; SCC, squamous cell carcinoma.

oxygen and nutrients which are essential for tumor cell growth, migration, and invasion. The balance between pro-angiogenic factors and anti-angiogenic molecules is critical for angiogenesis to occur. Vascular endothelial growth factor (VEGF), an important pro-angiogenic factor, is overexpressed in lung cancer tissues and is closely associated with tumor metastasis and prognosis of NSCLC patients, whose expression can be regulated by numerous factors (17). For example, epidermal growth factor receptor (EGFR) promotes the transcription of VEGF under both normal oxygen and hypoxic conditions in tumor cells (18). The expression of VEGF is reportedly induced by EGF (19). As a key anti-angiogenic molecule, VEGI also can down-regulate the expression of VEGF in endothelial cells and has been implicated in a variety of human tumors (20). Parr et al (9), carried out a study to determine the expression profile of VEGI in a cohort of 151 mammary tissue samples with a 6-year median follow-up and found that VEGI was expressed in the normal mammary tissue but it was dramatically reduced/absent in the breast tumor tissue samples. Moreover, VEGI level was positively correlated with the survival rate of breast cancer patients. A subsequent study (21) on the biological function of VEGI in breast cancer cell lines found that VEGI inhibited the migration, adhesion invasion, and vascularization capacity of MDA-MB-231 cells in vitro and in vivo. Similar results have been reported in other solid tumors $(12,13,22,23)$ such as bladder tumor, renal cell carcinoma, and pituitary adenomas implying that VEGI function as a tumor suppressor which negatively regulates neovascularization during tumorigenesis and progression of many solid tumors. Consistent with previous studies, absence or weak expression of VEGI was observed in $68.7 \%$ of NSCLC tissues. And MVD, a indicator of angiogenesis which can predict tumor growth, metastasis, and recurrence, was significantly increased in VEGI-poor group. Taken together, these observations suggest that VEGI may pose an inhibitory effect on NSCLC progression through inhibiting the intratumoral angiogenesis, at least partially.

Unfortunately, due to the limited number of samples, the correlation between VEGI expression and the pathological parameters of NSCLC patients could be made in this study. However, a mild association between VEGI expression and the histopathological type was observed. For instance, the 
A

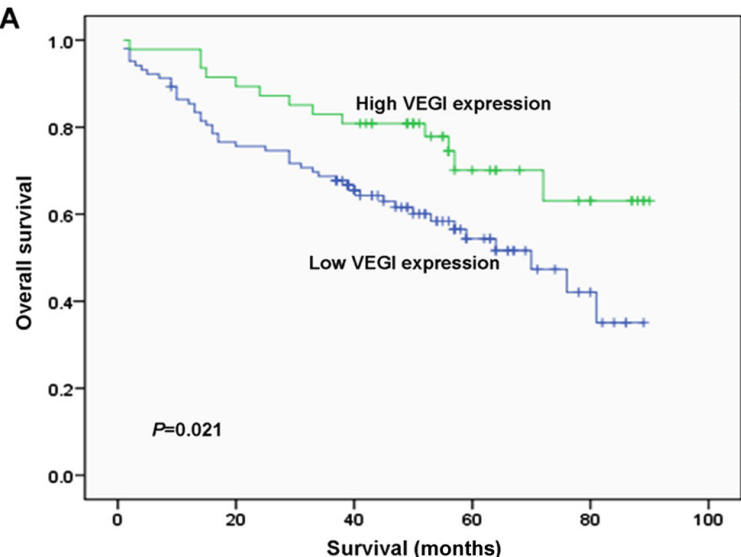

C

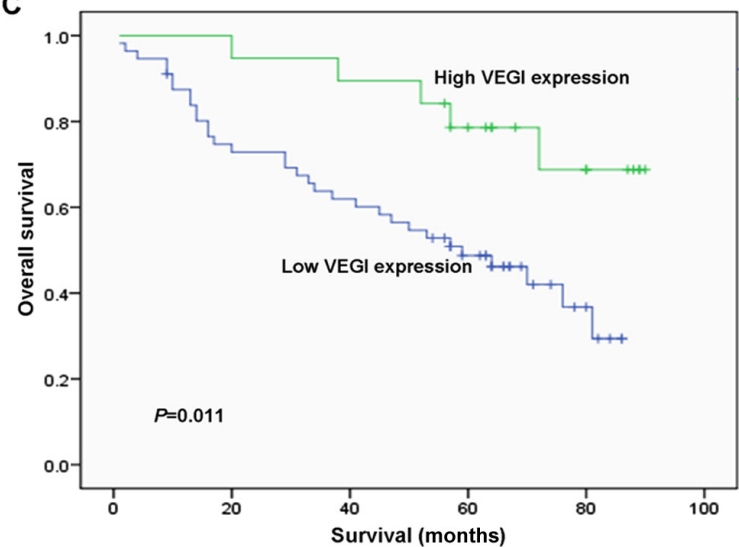

B

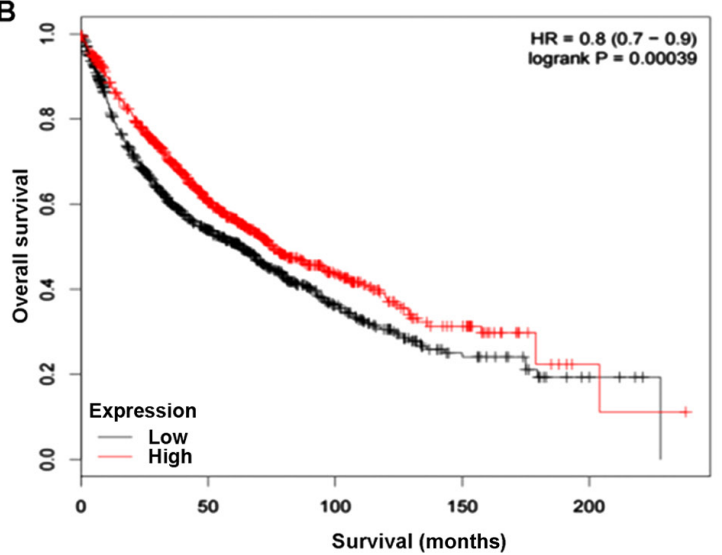

D

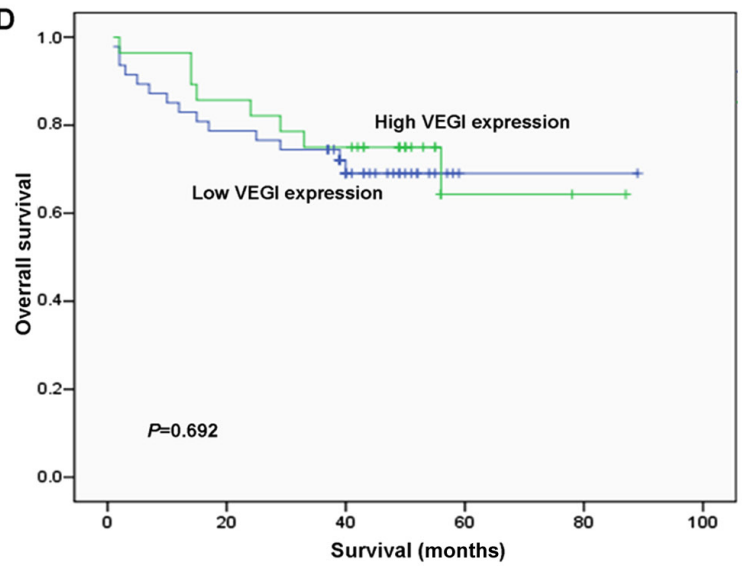

Figure 3. Kaplan-Meier survival curves according to VEGI expression in patients with NSCLC. (A) OS and VEGI expression in 150 patients with NSCLC (log-rank, P=0.021). (B) Kaplan-Meier plot analysis of 1,926 lung cancer cases on VEGI, available on the kmplot website (http://www.kmplot.com/analysis/index.php?p=background). (C) OS and VEGI expression in 75 patients with AC (log-rank, $\mathrm{P}=0.011)$. (D) OS and VEGI expression in 75 patients with squamous cell carcinoma (log-rank, $\mathrm{P}=0.692)$. - indicates complete cases; + indicates censored cases. VEGI, vascular endothelial growth inhibitor; NSCLC, NSCLC, non-small cell lung cancer; OS, overall survival; AC, adenocarcinoma.

down-regulation of VEGI was more prevalent in $\mathrm{AC}$ than that in squamous cell carcinoma (SCC). A negative correlation between VEGI expression and lymphovascular invasion and lymph node metastasis was observed in lung AC, which may be due to the differential contribution of the vasculature to the progress of lung cancer between SCC and AC. Moreover, NSCLC patients with reduced VEGI protein levels had a poor survival outcome than those with high levels of VEGI in AC, but this effect was observed in patients with squamous carcinoma, suggesting that the expression of VEGI protein may be a new prognostic parameter for AC patients but not SCC patients.

In summary, the down-regulation of VEGI expression was observed in NSCLC patients, which was correlated with the lower MVD, poor prognosis and shorter survival period for NSCLC, particularly in AC patients. Our results indicate that VEGI may be a tumor suppressor through inhibiting the intratumoral angiogenesis, at least partially, in NSCLC and a new prognostic marker for lung AC.

\section{Acknowledgements}

The authors would like to thank Professor Zhiwei Liu (Jiangsu Key Laboratory of Anesthesia and Analgesia Application Technology) for her excellent technical assistance.

\section{Funding}

The present study was supported by the Department of Science and Technology, Xuzhou, Jiangsu, China (grant no. KC17089) and the Jiang Su Provincial Medical Youth Talent (grant no. QNRC2016781).

\section{Availability of data and materials}

The datasets used and/or analyzed during the present study are available from the corresponding author on reasonable request.

\section{Authors' contributions}

SL and YX performed the research and analyzed the data. QL and SF analyzed the clinical data and contributed clinical samples. ZL, HL and JL performed immunohistochemical analysis and histologic assessment. JL and SL designed the experiments and wrote the manuscript. All authors read and approved the final manuscript.

\section{Ethics approval and consent to participate}

The present study was approved by the Regional Ethics Review Board of the Affiliated Hospital of Xuzhou Medical 
University, China (approval no. 2015-0629). Written informed consent was obtained from patients.

\section{Patient consent for publication}

Written informed consent was obtained from the patient for publication of this report.

\section{Competing interests}

The authors declare that they have no competing interests.

\section{References}

1. Torre LA, Bray F, Siegel RL, Ferlay J, Lortet-Tieulent J and Jemal A: Global cancer statistics, 2012. CA Cancer J Clin 65: 87-108, 2015.

2. Zhang S, Fu Y, Wang D and Wang J: Icotinib enhances lung cancer cell radiosensitivity in vitro and in vivo by inhibiting MAPK/ERK and AKT activation. Clin Exp Pharmacol Physiol 45: 969-977, 2018.

3. Sen Z, Zhan XK, Jing J, Yi Z and Wanqi Z: Chemosensitizing activities of cyclotides from Clitoria ternatea in paclitaxel-resistant lung cancer cells. Oncol Lett 5: 641-644, 2013.

4. Siegel RL, Miller KD and Jemal A: Cancer statistics, 2017. CA Cancer J Clin 67: 7-30, 2017.

5. Chen W, Zheng R, Baade PD, Zhang S, Zeng H, Bray F, Jemal A, $\mathrm{Yu}$ XQ and He J: Cancer statistics in China, 2015. CA Cancer J Clin 66: 115-132, 2016.

6. Lortet-Tieulent J, Soerjomataram I, Ferlay J, Rutherford M, Weiderpass $\mathrm{E}$ and Bray F: International trends in lung cancer incidence by histological subtype: Adenocarcinoma stabilizing in men but still increasing in women. Lung Cancer 84: 13-22, 2014.

7. Vansteenkiste J, Crinò L, Dooms C, Douillard JY, Faivre-Finn C, Lim E, Rocco G, Senan S, Van Schil P, Veronesi G, et al: 2nd ESMO Consensus Conference on Lung Cancer: Early-stage non-small-cell lung cancer consensus on diagnosis, treatment and follow-up. Ann Oncol 25: 1462-1474, 2014.

8. Siegel R, Naishadham D and Jemal A: Cancer statistics, 2012. CA Cancer J Clin 62: 10-29, 2012

9. Parr C, Gan $\mathrm{CH}$, Watkins $\mathrm{G}$ and Jiang WG: Reduced vascular endothelial growth inhibitor (VEGI) expression is associated with poor prognosis in breast cancer patients. Angiogenesis 9: 73-81, 2006.

10. Zhang N, Sanders AJ, Ye L and Jiang WG: Vascular endothelial growth inhibitor in human cancer (Review). Int J Mol Med 24: 3-8, 2009.

11. Zhang N, Sanders AJ, Ye L, Kynaston HG and Jiang WG: Vascular endothelial growth inhibitor, expression in human prostate cancer tissue and the impact on adhesion and migration of prostate cancer cells in vitro. Int J Oncol 35: 1473-1480, 2009.
12. Zhang N, Sanders AJ, Ye L, Kynaston HG and Jiang WG: Expression of vascular endothelial growth inhibitor (VEGI) in human urothelial cancer of the bladder and its effects on the adhesion and migration of bladder cancer cells in vitro. Anticancer Res 30: 87-95, 2010.

13. Wu L, Li X, Ye L, Shayiremu D, Deng X, Zhang X, Jiang W, Yang Y, Gong K and Zhang N: Vascular endothelial growth inhibitor 174 is a negative regulator of aggressiveness and microvascular density in human clear cell renal cell carcinoma. Anticancer Res 34: 715-22, 2014

14. Zhao Q, Liu T, Hong B, Wang F, Zhou C, Du X, Chen S, Deng X, Duoerkun S, Li Q, et al: Vascular endothelial growth inhibitor, a cytokine of the tumor necrosis factor family, is associated with epithelial-mesenchymal transition in renal cell carcinoma. Appl Immunohistochem Mol Morphol 26: 727-733,2018.

15. Hou W, Medynski D, Wu S, Lin X and Li LY: A new isoform of TNFSF15, specifically eliminates tumor vascular endothelial cells and suppresses tumor growth. Clin Cancer Res 11: 5595-5602, 2005.

16. Liang PH, Tian F, Lu Y, Duan B, Stolz DB and Li LY: Vascular endothelial growth inhibitor (VEGI; TNFSF15) inhibits bone marrow-derived endothelial progenitor cell incorporation into Lewis lung carcinoma tumors. Angiogenesis 14: 61-68, 2011.

17. Chen Y, Mathy NW and Lu H: The role of VEGF in the diagnosis and treatment of malignant pleural effusion in patients with non-small cell lung cancer (Review). Mol Med Rep 17: 8019-8030, 2018

18. Karoor V, Le M, Merrick D, Fagan KA, Dempsey EC and Miller YE: Alveolar hypoxia promotes murine lung tumor growth through a VEGFR-2/EGFR-dependent mechanism. Cancer Prev Res (Phila) 5: 1061-1071, 2012.

19. Yu X, Li W, Deng Q, You S, Liu H, Peng S, Liu X, Lu J, Luo X, Yang L, et al: Neoalbaconol Inhibits angiogenesis and Tumor Growth by suppressing EGFR-mediated VEGF production. Mol Carcinog 56: 1414-1426, 2017.

20. Zhang K, Cai HX, Gao S, Yang GL, Deng HT, Xu GC, Han J, Zhang QZ and Li LY: TNFSF15 suppresses VEGF production in endothelial cells by stimulating miR-29b expression via activation of JNK-GATA3 signals. Oncotarget 7: 69436-69449, 2016.

21. Gao Y, Ge Z, Zhang Z, Bai Z, Ma X and Wang Y: Vascular endothelial growth inhibitor affects the invasion, apoptosis and vascularisation in breast cancer cell line MDA-MB-231. Chin Med J (Engl) 127: 1947-1953, 2014.

22. Jia W, Sander AJ, Jia G, Ni M, Liu X, Lu R and Jiang WG: Vascular endothelial growth inhibitor (VEGI) is an independent indicator for invasion in human pituitary adenomas. Anticancer Res 33: 3815-3822, 2013.

23. Duan L, Yang G, Zhang R, Feng L and Xu C: Advancement in the research on vascular endothelial growth inhibitor (VEGI). Target Oncol 7: 87-90, 2012.

This work is licensed under a Creative Commons Attribution-NonCommercial-NoDerivatives 4.0 International (CC BY-NC-ND 4.0) License. 